\title{
COVID-19 Vaccination Strategy in Germany
}

\section{Pfeiffer-Ruiz (Michael Pfeiffer-Ruiz), V. Schroder (Vitali Schroder)}

SEUC PhDProgramme, Germany.

\section{E-mail address:}

m.pfeiffer-ruiz@web.de

\section{Reprint address:}

Michael Pfeiffer-Ruiz

SEU PhD Programme

Badstrasse 5

92318 Neumarkt

Bavaria, Germany

Source: Clinical Social Work and Health Intervention

Volume: 12

Issue: 2

Pages: $31-34$

Cited references: 8

\section{Reviewers:}

Clauss Muss

I-GAP Zurich, $\mathrm{CH}$

Roberto Cauda

Institute of Infectious Diseases, Catholic University of the Sacred Heart, Rome, IT

\section{Keywords:}

COVID-19 Vaccine. Safety and Efficacy COVID-19 Vaccines. Vaccine Development.

\section{Publisher:}

International Society of Applied Preventive Medicine i-gap

CSWHI 2021; 12(2): 31 - 34; DOI: 10.22359/cswhi_12_2_05 CC Clinical Social Work and Health Intervention

\section{Abstract:}

\begin{abstract}
Vaccines are needed to reduce the mortality and economic damage caused by COVID-19. To date there are three approved vaccines in the European Union created by BioNTech/Pfizer, Moderna and AstraZeneca, but due to the high demand globally there are still shortages, forcing governments to create strategies to immunize their population prioritizing their citizens according to their risk evaluation and their systemic relevance. This review specifies on the German vaccination strategy.
\end{abstract}

\section{Introduction}

The COVID-19 pandemic has been one of the greatest challenges of the century for the health industry considering the high mortality and rapid spread of the Coronavirus Disease 2019. Therefore the academic community, industry and government sectors are working tightly together to develop and test a variety of vaccines at an unprecedented pace
(1). This review is focused on the vaccines that have been approved by the European Union and the vaccination strategy established for Germany. So far there have been three vaccines that have passed the clinical trials and are approved by the European Commission to be distributed along the European population with the goal of reaching herd immunity and reducing the mortality rate. 


\section{Covid-19 vaccines approved by the European Union}

\section{1. BioNTech/Pfizer vaccine}

The BNT162b2 mRNA Covid-19 vaccine developed by the German biotechnology company BioNTech in cooperation with the American pharmaceutical corporation Pfizer is the first vaccine to have passed the clinical trials and to receive approval by the European Commission on 22. December 2020.

The BNT162b2 is a lipid nanoparticle-formulated, nucleoside-modified RNA vaccine that encodes a prefusion stabilized, membrane-anchored SARS-CoV-2 full-length spike protein. It is applied in a two dose regimen (30 $\mu \mathrm{g}$ per dose) which is administered 21 days apart and has been proven to be $95 \%$ effective in preventing a COVID-19. It is recommended for adults and adolescents 16 years of age or older and its safety profile was characterized by short-term, mild to moderate pain at the injection site, fatigue and headache.(2)

\section{2. Moderna vaccine}

The mRNA-1273 SARS-CoV-2 vaccine developed by the American pharmaceutical company Moderna was the second COVID-19 vaccine to receive approval by the European Commission on 6. January 2021.

It consists of a lipid-nanoparticle-encapsulated nucleoside modified mRNA vaccine expressing the prefusion-stabilized spike glycoprotein of SARS-CoV-2 and is applied in two doses (100 $\mu \mathrm{g}$ per dose) administered intramuscularly 28 days apart. It is recommended for adults (over 18 years) and has shown an efficacy of $94.1 \%$ and asides from transient local and systemic reactions no safety concerns were identified. $(3,4)$

\section{3. Oxford-AstraZeneca vaccine}

The chimpanzee adenovirus vectored vaccine ChAdOx1 nCoV-19 (AZD 1222) developed by the multinational pharmaceutical and biopharmaceutical company AstraZeneca with its headquarters in Cambridge, England is the latest vaccine to have received a green light by the European Commission on 29 January 2021, although its application has been restricted to the ages between 18 and 64 due to missing valid test data for an older population.
The vectored vaccine is administered in two doses containing $5 \times 10^{10}$ viral particles with 28 to 84 days between the two doses. It has been proven to have a vaccine efficacy of $70.4 \%$ after two doses and protection of $64.1 \%$ after at least one standard dose against symptomatic disease, with no safety concerns. $(5,6)$

\section{Vaccination strategy applied in Germany}

Due to the shortage of available vaccines in Germany and the European Union in general, the German Federal Health Administration was forced to elaborate a vaccination strategy in cooperation with the Robert Koch Institute to reduce the harm caused by this pandemic and prioritizing of individuals who:

- have an increased risk of a heavy or deadly course of COVID-19

- have a high exposition to the virus due to their work

- are in frequent contact with groups of people categorized as ,high risk“ with elevated probability of pathogen transmission.(7)

Currently there are six stages of vaccination in Germany:

\section{Stage 1:}

- Individuals over the age of 80

- Residents of nursing homes

- Medical staff with especially increased risk of exposition, including emergency wards, medical care of COVID-19 patients, emergency medical services and employees in medical sectors where aerosol-generating procedures are performed on COVID-19 patients (e.g. In- and extubation, bronchoscopy or laryngoscopy,...)

- Personnel in medical facilities with close contact to vulnerable groups, such as geriatric care facilities, institutions treating immunocompromised, oncologic, palliative patients and mobile vaccination teams.

- Nursing staff in ambulant or stationary care

- Other employees of residential care facilities for the elderly (7)

\section{Stage 2:}

- Individuals between the ages of 75 and 79

- People with trisomy 21 (Down’s syndrome)

- Institutional residents with dementia or mental disabilities

- Medical staff with high risk of exposition, like isolation wards, general doctor's/pediatricians offices, on duty emergency medical service, 
transport of emergency patients, ENT, ophthalmology or dental clinics, SARS-CoV-2 test centers and public health service.

- Employees in ambulant or stationary care of patients with dementia or mental disabilities (7)

\section{Stage 3:}

- Individuals between the ages 70 and 74

- Persons with pre-existing conditions considered high risk, such as chronic liver disease, cancer (not in remission), psychiatric illness (e.g. bipolar disorder, schizophrenia, severe depression), dementia, Diabetes mellitus (HbA1c $\geq 58 \mathrm{mmol} / \mathrm{mol}$ or $\geq 7.5 \%$ ), obesity (BMI $>30$ ), malignant haematological disorders and chronic renal failure

- Residents and staff in shared accommodations

- Close contact persons of pregnant women or persons with high risk

- Personnel in medical facilities with moderate risk of exposition like employees working with pregnant patients, blood donations or stationary vaccination centres, cleaning staff, relevant personnel for hospital infrastructure (7)

\section{Stage 4:}

- Individuals between the ages of 65 and 69 years

- Persons with pre-existing conditions considered moderate risk, including diseases of the heart or the central nervous system, diabetes mellitus $(\mathrm{HbA} 1 \mathrm{c}<58 \mathrm{mmol} / \mathrm{mol}$ or $<7,5 \%)$, cancer (in remission), rheumatic or autoimmune illnesses, hypertension and asthma

- Close contact persons of people with moderate risk

- Personnel in medical facilities with low risk of exposition like laboratory staff and workforce not dealing with patients with (suspected) infectious diseases and not performing aerosol generating procedures

- Teachers and childcare workers

- Persons with precarious working and/or living conditions (7)

\section{Stage 5:}

- Individuals between the ages of 60 and 64 years

- Previously not mentioned occupational groups, like personnel in key positions of the state and local government, retail workers, security and critical infrastructure personnel (7)

\section{Stage 6:}

- Remaining part of the population under the age of 60 (7)

\section{Materials and methods}

The main search engines used were PubMed, Google Scholar and Web of Science using the keywords: „,SARS-CoV-2 vaccine“, „COVID-19 vaccine“, „BioNTech/Pfizer vaccine“, ,Moderna vaccine“, „Astra-Zeneca vaccine“, „Safety and Efficacy COVID-19 vaccines“, ,Vaccine development".

Included in this review were articles, case studies, efficacy trials and systematic reviews as well as information gathered from the official website of the German Federal Government and the Robert-Koch Institute published on December 2020 or later. The exclusion criteria consisted in: articles not related to the topic; animal studies; articles published before December 2020 .

\section{Results}

The currently approved vaccinations have proven to be very efficient in short term prevention of a severe course of COVID-19, but so far there is not enough data to make viable statements about prevention of transmission and long term immunity.

Also due to the recent nature of events and Germany currently being between stages 1 and 2 of their vaccination plan it is yet too early to make any declaration about the efficiency of the applied strategies even though a decrease of the number of cases can be observed, but it is mostly attributed to the implemented measures of containment.

In some aspects of it there might still be some room for discussion as not all of the listed professions might feel they are being treated fairly, especially the teachers and childcare workers, because it is very hard to maintain the established measures of prevention in the schools and kindergartens and they are supposed to be reopened soon, yet they are categorized as a profession of low risk.

\section{Conclusion}

Even though there are vaccines available, there still are shortages, forcing the German government to implement a vaccination plan as well as a priority system to reduce the harm caused by the Coronavirus, meaning that the end of this pandemic remains yet to be seen. The vaccination strategy is not a fixed structure that can be changed and adapted to the needs of the current situation. 


\section{References}

1. LI YD, CHI WY, SU JH, FERRALL L, HUNG CF, WU TC (2020) Coronavirus vaccine development: from SARS and MERS to COVID-19. J Biomed Sci. 2020;27(1): p 104.

2. POLACK FP, THOMAS SJ, KITCHIN N, ABSALON J, GURTMAN A, LOCKHART S et al. (2020) Safety and Efficacy of the BNT162b2 mRNA Covid-19 Vaccine. N Engl J Med. 2020;383(27): pp 2603-15.

3. OLIVER SE, GARGANO JW, MARIN M, WALLACE M, CURRAN KG, CHAMBERLAND M, et al. (2021) The Advisory Committee on Immunization Practices' Interim Recommendation for Use of $\backslash$ Moderna COVID19 Vaccine - United States, December 2020. MMWR Morb Mortal Wkly Rep. 2021;69(5152): pp 1653-6.

4. BADEN LR, EL SAHLY HM, ESSINK B, KOTLOFF K, FREY S, NOVAK R, et al. (2021) Efficacy and Safety of the mRNA-1273 SARS-CoV-2 Vaccine. N Engl J Med. 2021;384(5): pp 403-16.

5. VOYSEY M, CLEMENS SAC, MADHI SA, WECKX LY, FOLEGATTI PM, ALEY PK, et al. (2021) Safety and efficacy of the ChAdOxI $n C o V-19$ vaccine (AZD1222) against SARSCoV-2: an interim analysis of four randomised controlled trials in Brazil, South Africa, and the UK. Lancet. 2021;397(10269): pp 99-111.

6. KNOLL MD, WONODI C (2021) OxfordAstraZeneca COVID-19 vaccine efficacy. Lancet. 2021;397(10269): pp 72-4.

7. KOCH-INSTITUT R. STUFENPLAN DER STIKO ZUR PRIORISIERUNG DER COVID-19-IMPFUNG ROBERT KOCH-INSTITUT WEBSITE2021 [Available from: https://www.rki.de/DE/Content/Infekt/Impfen/ImpfungenAZ/COVID- 19/Stufenplan.htmlAvailable from: \jsessionid=696984FCEC459FB9DC34 A61D067CD1FC.internet061.

8. RADI F, BUDZELOVA K, OLAH M, MUSS C (2021) Late psychosocial consequencesfrom HIV to Covid. Clin Soc Work and Health Interv.12.2021.2.6-7.10.22359/cswhi_12_2_15. 